\title{
A FORMAÇÃO DO PROFESSOR E SEU REFLEXO NA PRÁXIS EDUCATIVA
}

\author{
Zeina Rebouças Corrêa Thomél \\ Gisele de Brito Braga² \\ lolanda Domingos Estêvão David Lameira ${ }^{3}$
}

\begin{abstract}
RESUMO
O artigo foi elaborado tendo por base os ensinamentos na disciplina Formação e Práxis do Educador: possibilidades, tensões e contradições. Tem por objetivo refletir sobre o tema: A Formação do Professor e seu Reflexo na Práxis Educativa, desenvolvendo as questões da educação, da pesquisa e a reflexão sobre a formação docente e do trabalho pedagógico como ato educativo intencional, com embasamento teórico, especialmente em: Arroyo, Brito, Charlot, Freire, Ghedin, Giroux, Henández, Imbernón, Mello, Nielsen Neto, Perrenoud, Pimenta, Schmitz e Shön. O tema desenvolvido nos três itens visa pensar a educação como processo de construção e transmissão de conhecimentos, valores culturais da comunidade social em que está inserido. Apresentar as concepções de formação docente de "professor reflexivo" de Shön e de "intelectual crítico reflexivo", desenvolvida, especialmente, por Pimenta e Ghedin, assim como, evidenciar o trabalho pedagógico como ato educativo intencional, em que nem o ensino e nem a aprendizagem podem ser uma simples transposição automática e que ambos são indissociáveis da forma escolar de educação.
\end{abstract}

Palavras-chave: Educação. Formação de professores. Práxis educativa.

\section{TEACHER TRAINING AND HIS REFLECTION IN EDUCATIONAL PRACTICE}

\begin{abstract}
This article has been prepared based on the teachings on discipline Training and praxis of the educator: possibilities, tensions and contradictions. Aims to reflect on the theme: training of the teacher and your reflection in Educational Praxis, developing the issues of education, research and reflection in teacher education and the pedagogical work as educational Act intentionally, with theoretical basis, especially in: Arroyo, Brito,
\end{abstract}

\footnotetext{
I Pós-Doutora pela Universidade Federal de Santa Catarina (UFSC) - SC - Brasil. Doutora em Engenharia de Produção pela Universidade Federal de Santa Catarina (UFSC) - SC - Brasil. Professora da Universidade Federal do Amazonas (UFAM) - Manaus, AM - Brasil. Orcid iD: https://orcid.org/0000-0002-7483-8186. E-mail: zeinathome@gmail.com

2 Doutoranda UFAM - Universidade Federal do Amazonas - PPGE - Manaus - AM - Brasil. Orcid iD: https://orcid.org/0000-0002-6610-4959. E-mail: giselebraga@mac.com

3 Doutoranda UFAM - Universidade Federal do Amazonas - PPGE - Manaus - AM - Brasil. Orcid iD: https://orcid.org/0000-0002-6017-2846. E-mail: iolalameira@yahoo.com.br
}

Revista Exitus, Santarém/PA, Vol. 11, p. 01 - 22, e020191, 2021. 
Charlot, Freire, Ghedin, Giroux, Henández, Imbernón, Mello, Nielsen Neto, Perrenoud, Pimenta, Schmitz and Shön. The theme developed in the three items aims to consider education as a process of construction and transmission of knowledge, cultural values of social community in which it is inserted. Present conceptions of teacher education of "reflective" Shön teacher and "intellectual critic reflexion", developed, specially by Pimenta e Ghedin, as with intentional pedagogic work and learning are both indissociable in formal education.

Keywords: Education. Teacher Formation. Educational Praxis.

\section{LA FORMACIÓN DEL PROFESORADO Y SU REFLEXIÓN EN LA PRÁCTICA EDUCATIVA}

\section{RESUMEN}

El artículo fue elaborado a partir de las enseñanzas en la disciplina Formación y Praxis del Educador: posibilidades, tensiones y contradicciones. Se pretende reflexionar sobre el tema: Formación docente y su reflexión en la praxis educativa, desarrollando los temas de educación, investigación y reflexión sobre la formación docente y el trabajo pedagógico como un acto educativo intencional, con base teórica, especialmente en: Arroyo, Brito, Charlot, Freire, Ghedin, Giroux, Henández, Imbernón, Mello, Nielsen Neto, Perrenoud, Pimenta, Schmitz y Shön. El tema desarrollado en los tres ítems tiene como objetivo pensar la educación como un proceso de construcción y transmisión de conocimientos, valores culturales de la comunidad social en la que se inserta. Presentar las concepciones de formación docente de "maestro reflexivo" de Shön y de "intelectual crítico reflexivo", desarrolladas especialmente por Pimenta y Ghedin, así como destacar el trabajo pedagógico como un acto educativo intencional, en el que ni la enseñanza ni el aprendizaje pueden ser una simple transposición automática y que ambos son inseparables de la forma escolar de educación.

Palabras clave: Educación. Formación docente. Praxis educativa.

\section{EDUCAÇÃO}

O termo educação, segundo Abbagnano (1970, p. 288), deriva do latim educativo, ducere e, em geral, significa "a formação do homem, o amadurecimento do indivíduo através da transmissão e o aprendizado das técnicas culturais".

A educação, segundo Schmitz (1984, p. 13), "é um fenômeno ou processo prático, concreto, vital, referindo-se a pessoas concretas que precisam de princípios orientadores e norteadores para suas próprias ações e para o auxílio a outras pessoas". 
Para Nielsen Neto (1998, p. 12), a palavra educação possui vários significados: no sentido comum refere-se a cortesia, polidez, civilidade. Etimologicamente é derivada da palavra latina ducere e significa conduzir, comandar, discernir, marchar à frente, etc. A partir de tal entendimento, educar "significa transmitir, de geração em geração, os valores culturais da comunidade social em que o homem está inserido e da qual recebe um conjunto de técnicas normativas que lhe permite satisfazer suas necessidades biológicas, físicas, culturais, e integrar-se na sociedade".

São muitos os autores que constroem ideias e teorias sobre o fazer educação. Neste trabalho, em especial neste item, iremos trabalhar a questão tendo por suporte, especialmente, as ideias de Imbernón, contidas na sua obra "A Educação no Século XXI: os desafios do futuro imediato".

Inerente à natureza humana na sua dupla estrutura corpórea e intelectiva, a educação é criadora das condições especiais para a manutenção e transmissão de sua forma particular de existir. Por meio da vontade consciente e da razão ela se impõe como o instrumento através do qual a comunidade humana transmite suas peculiaridades físicas e intelectuais. Por isso mesmo, todo povo que alcança um certo grau de desenvolvimento, sente-se naturalmente inclinado à prática da educação que, através do esforço consciente do conhecimento e da vontade, conduz progressivamente o espírito humano à descoberta de si próprio e cria, através do conhecimento do mundo exterior e interior, formas melhores de existência para o homem.

No centro da vida social e no fazer educação afirmam-se as instituições escolares que se transformam no tempo, mas que mantêm sua centralidade na figura do educador como iluminador dos fins e dos processos de educar elaborados segundo um ideal de formação humana. O que é uma sociedade, o que são seus membros, qual o futuro de uma e de outros são aspectos que não podem ser pensados à margem do que foi e é o seu sistema educativo. 
A educação não é uma propriedade individual, mas pertence por essência à comunidade [...]. Em nenhuma parte, o influxo da comunidade nos seus membros tem maior força que no esforço constante de educar, em conformidade com o seu próprio sentir, cada nova geração [...]. Toda educação é assim o resultado da consciência viva de uma comunidade humana, quer se trate de família, de uma classe ou de uma profissão, quer se trate de um agregado mais vasto, como um grupo étnico ou um Estado (JAEGER, 2001, p. 4).

Por não ser um credo, a educação está em contínua pugna consigo mesma fazendo com que aquele que a ela se dedique queira viver para participar do desenvolvimento comum da humanidade. Todavia, parece que o nosso momento histórico nos coloca um dilema que compete a nós educadores resolver: tombar no abismo da ruína da educação e do homem ou buscar ânimo para nos transformarmos em educadores e deixar a condição de meros repassadores de informação. Como força que faz jorrar a luz para que o homem encontre o seu caminho, a educação não pode ser minimizada e nem negligenciada.

A universalização da educação através da escolaridade formal é, segundo Imbernón (2000), uma importante experiência na configuração das subjetividades individuais, na percepção de si mesmo e na identidade pessoal. As respostas que cada um de nós tem para as perguntas do que é, quem pensa que é e como se sente e percebe a si mesmo tem muito a ver com a educação recebida porque, sem dúvida, a educação favorece um enriquecimento da subjetividade que dá certo poder sobre a ação. Por isso mesmo espera-se que o eu do homem e da mulher modernos escolarizados seja um eu reflexivo, que pondere sobre as ações, mantendo o controle delas e estando desligado das submissões.

A educação formal recebida como forma de viver a cultura é de fundamental importância para as relações interpessoais dos indivíduos porque o nível e o tipo de educação recebida oferecem conteúdos através dos quais são feitas aproximações e diferenciações entre as pessoas e na estruturação das relações sociais em geral. 
O que os indivíduos e a sociedade são, o que poderão ser, não pode ser explicado ou projetado, sem serem considerados os efeitos dos sistemas educativos. Esta é uma condição essencial deste século. [...] A educação será a encarregada de unir indissociavelmente tanto a tradição valorizada em cada momento como as disponibilidades e as capacidades para mantê-la em constante processo de reconstrução. O passado cultural é a fonte do presente e o material substancial do futuro ao ser refeito no presente. Não há futuro sem raízes previamente assentadas sobre as quais se erguer (IMBERNÓN, 2000, p. 45).

A missão da educação é situar-nos em um determinado momento levando em consideração um passado refletido e avaliado, criticando o presente e abrindo-se para o futuro. Essa concepção constitutiva dos sujeitos plenos explica o reconhecimento da educação no século XX e XXI como um direito universal do homem e da mulher e, de modo particular, da criança. Por estar ligado a dignidade da pessoa humana e possibilitar a todos 0 enriquecimento da própria vida, possui valor em si mesma e se constitui como direito fundamental da humanidade.

Ainda, segundo Imbernón (2000), é importante que no campo educativo termos, pelo menos, dois tipos de olhares: um olhar imediato, próximo, de curto alcance que nos ajuda a resolver os problemas cotidianos que não nos permitem erguer os olhos; um outro mais amplo e mais profundo que pode nos ajudar a avaliar o legado do passado, o que construímos no presente, o que podemos vislumbrar para o futuro, o que pretendemos conseguir a curto e médio prazos e que mecanismos iremos pôr em funcionamento para realizar nossas aspirações.

Se detivermos nosso olhar em nosso meio educativo, poderemos perceber que foi sendo construído um discurso, mais simbólico do que real, que se opõe frontalmente a qualquer manifestação explícita ou oculta da racionalidade tecnocrática, seja na organização dos conteúdos curriculares, seja nas formas de gestão e controle técnicoburocrático baseados mais na reprodução do que na inovação educativa [...]. Trata-se uma vez mais, da perversão: apropriar-se da palavra, da ideia, mas sem que se traduza em ação. [...] muitos dos postulados vanguardistas avançaram mais no terreno das ideias do que no das práticas alternativas (IMBERNÓN, 2000, p. 79).

Com vistas a superação de tal situação, o autor acima referido, propõe o desenvolvimento de quatro ideias: a) a recuperação, por parte dos 
professores e de qualquer agente educativo, do controle sobre o processo de trabalho, desvalorizado em consequência da fragmentação organizativa e curricular, do isolamento, da autonomia fictícia e da rotinização e mecanização laboral; b) o questionamento da legitimação do conhecimento ou do discurso pedagógico oficial que se comunica nas instituições educativas, que julgamos, sob todos os aspectos, estreito e insuficiente para o próximo (este) século e, não esqueçamos, que é parte do conhecimento que trata de pôr os estudantes em contato com os diversos campos e vias do saber, da experiência e da realidade; c) o papel da comunidade como verdadeira integrante do processo educativo porque a educação não pode ser exercida apenas pelos professores porque a instituição educativa já não possui um saber inquestionável, mas este se expande no tecido social, e para fazê-lo seu a instituição educativa necessita da inter-relação e da participação de toda a comunidade; d) A escola universal estendida a todas as classes sociais através de novos componentes que voltem a legitimar um sistema educativo democrático.

É de fundamental importância no desenvolvimento do processo educativo, no entendimento de Imbernón (2000), a instauração de uma pedagogia da pergunta e não só da resposta que favoreça uma aprendizagem baseada no diálogo e não apenas no monólogo. Nessa perspectiva o novo papel do professor, e de toda pessoa que se dedique a qualquer atividade educativa deve focar não no fornecimento do saber, mas especialmente como gestor e mediador de aprendizagem. A educação precisa recuperar os princípios de convivência baseados na liberdade, no diálogo e na responsabilidade para que possa propiciar uma aprendizagem dialógica onde a relação educativa se desenvolva como um processo de comunicação intersubjetiva. Pretender uma escola crítica, democrática e de qualidade exige inexoravelmente imaginá-la em uma sociedade mais igualitária e justa.

A educação deve possibilitar que, através de um processo reflexivo e crítico, cada indivíduo reconstrua conscientemente seu pensamento para que, através de sua própria experiência e a dos outros, adquira autonomia 
intelectual para analisar criticamente os processos e os conteúdos socializadores recebidos e articulá-los. Mais do que transmitir conhecimentos, a educação deve formar indivíduos capazes de buscar e manejar por sua conta os conhecimentos que Ihes sejam necessários. "Mais do que transmitir informação, a função educativa da escola contemporânea deve orientar-se para provocar a organização racional da informação fragmentada recebida e a reconstrução crítica das preocupações acríticas (PÉREZ GÓMEZ, 1992 apud IMBERNÓN, 2000, p. 189).

\section{PESQUISA E REFLEXÃO NA FORMAÇÃO DOCENTE}

Enquanto o trabalho do professor era visto apenas como transmissão de conteúdos pré-estabelecidos, não se percebia a necessidade da pesquisa. A partir de novos olhares sobre o processo de ensino-aprendizagem surgidos, principalmente, nas primeiras décadas do século XX, se estabelecem novas compreensões e nova literatura que dão ênfase a pesquisa como um dos elementos base para a formação do professor e para o fazer educação.

No campo educativo é a pesquisa que alimenta a atividade de ensino e promove a sua atualização frente à realidade do mundo. Ela vincula pensamento e ação e possibilita explicações ou soluções de problemas que levam não apenas a aquisição de novos conhecimentos, mas, também, favorecem uma determinada intervenção. Pesquisa-se para entender uma realidade, encontrar e determinar múltiplos fatores da situação ou do problema e compreender sua complexidade para, a partir dessa compreensão, divulga-la, explica-la aos outros e, posteriormente, aplicá-la ao campo de estudo (BRITO, p. 13).

Esse entendimento é compartilhado, também, por Ghedin (2009) ao afirmar que a pesquisa se constitui em eixo central da elaboração de novos saberes e de novos conhecimentos a respeito da realidade educacional, transformando-a em objeto a investigar.

É pela prática da pesquisa que aprendemos a reelaborar o conhecimento, para aprender a reinterpretar a realidade e aprender a reunir as informações para traduzi-las num conhecimento próprio e pessoal, que é um modo de interpretar o mundo, a realidade e propor novas formas de agir e de ser do/no mundo (GHEDIN, 2009, p. 17). 
Os entendimentos dos autores acima referidos, vão ao encontro da ideia de Paulo Freire que nos diz ser a pesquisa uma atividade essencial para o exercício da reflexão e da docência porque proporciona ao professor, elementos para refletir sobre sua prática de forma mais sistemática e rigorosa.

Não há ensino sem pesquisa e pesquisa sem ensino. Esses que-fazeres se encontram um no corpo do outro. Enquanto ensino continuo buscando, reprocurando. Ensino porque busco, porque indaguei, porque indago e me indago. Pesquiso para constatar, constatando, intervenho, intervindo educo e me educo (FREIRE, 2004, p. 16).

No entendimento de Bernard Charlot (2001, p. 6), a ideia de formação implica a de indivíduo que deve ser dotado de certas competências cujo conteúdo e natureza podem variar segundo o momento histórico. Formar alguém é torná-lo capaz de executar práticas pertinentes a uma dada situação em função de um fim que se deseja atingir. "O indivíduo formado é aquele, que através de suas práticas, é capaz de mobilizar os meios e as competências necessárias para atingir um fim determinado em uma dada situação".

Diferente disso, a ideia de ensino implica em um saber a transmitir, não importando quais sejam as modalidades de transmissão, o que implica em: o saber adquirir, que é o objetivo, o ponto de referência do processo, sua razão de ser; o aluno ou o aprendiz e o mestre, cuja função é servir de mediador entre o aluno e o saber. A lógica do ensino é então aquela do saber ensinar - saber constituído em sistema e discurso construído através de uma coerência interna. A lógica da formação é aquela das práticas, por definição contextualizadas e organizadas para atingir um fim, enquanto a lógica do ensino é a dos discursos constituídos em sua coerência interna.

O grande desafio para a formação dos docentes, segundo Imbernón (2000), é requalificá-lo para torná-lo um profissional reflexivo, especialmente sobre suas próprias práticas. Neste sentido se faz necessária a modificação racional da formação docente para que seja valorizada a sua prática e fortalecida sua autonomia. Isto significa proporcionar a superação do seu 
papel de transmissor passivo para aproximá-lo do intelectual transformador, crítico e emancipador.

O pensamento crítico reflexivo pode trazer, conforme Imbernón (2000), contribuições para a reinvenção da formação. Pensar as instituições educativas a partir desses fundamentos parece ser um exercício de autonomia intelectual que permite transcender os estreitos limites unidirecionais do discurso hegemônico e sua lógica tecnocrata da racionalidade instrumental que vigoravam e ainda vigoram nas políticas educativas nacionais. Contudo, para que se compreenda o movimento teórico de compreensão do trabalho docente denominado de "professor reflexivo" precisamos apreender os seus pressupostos, os seus fundamentos.

Se a reflexão é algo inerente aos seres humanos, os professores como seres humanos são reflexivos. Então, porque a expressão professor reflexivo se tornou objeto de estudo e passou a ser requerido como condição da formação docente?

Conforme Pimenta (2002), a expressão tomou conta do cenário educacional a partir dos anos 90 do século XX, com Donald Schön (EUA), ao realizar atividades relacionadas com reformas curriculares nos cursos de formação de profissionais. Naquele momento a palavra reflexão, utilizada como atributo próprio do ser humano passou a ser utilizada, também, como movimento teórico de compreensão do trabalho docente. O referido movimento

Propõe que a formação dos profissionais não mais se dê nos moldes de um currículo normativo que primeiro apresenta a ciência, depois a sua aplicação e por último um estágio que supõe a aplicação pelos alunos dos conhecimentos técnico-profissionais. O profissional assim formado, conforme a análise de Shön, não consegue dar respostas às situações que emergem no dia-a-dia profissional, porque estas ultrapassam os conhecimentos elaborados pela ciência e as respostas técnicas que esta poderia oferecer ainda não estão formuladas (PIMENTA, 2002, p. 19).

Deste modo, conforme ensina Pimenta (2002), ao valorizar "a experiência e a reflexão na experiência" como fizera Dewey, e o conhecimento tácito, conforme Luria e Polanyi, Shön propõe uma formação profissional sustentada numa "epistemologia da prática" que atribui valor 
predominante da prática, sustentada na reflexão, na análise e na problematização, como o momento de construção do conhecimento. Nela, segundo Shön, ao enfrentar situações novas que ultrapassem a rotina, os profissionais criam, constroem novas soluções, novos caminhos, que acontecem por um processo de "reflexão na ação" que possibilita criar um repertório de experiências utilizáveis em situações similares. Contudo, novas situações surgem e superam o repertório criado suscitando novas buscas, novas análises, uma contextualização, uma problematização, um diálogo com outras perspectivas, uma apropriação de teorias sobre o problema, abrindo com isso, perspectivas para a valorização da pesquisa na ação dos profissionais. Ao fazer isto, coloca as bases para o que se denomina "professor pesquisador".

Ao analisar a proposta de Shön e as contribuições de sua teoria, Pimenta afirma que

Encontramos em Shön uma forte valorização da prática na formação dos profissionais; mas uma prática refletida, que thes possibilite responder às situações novas, nas situações de incertezas e indefinição. Portanto, os currículos de formação de profissionais deveriam propiciar o desenvolvimento da capacidade de refletir. Para isso, tomar a prática existente (de outros profissionais e dos próprios professores) é um bom caminho a ser percorrido desde o início da formação, e não apenas ao final, como tem ocorrido com o estágio. [...] o ensino como prática reflexiva tem se estabelecido como uma tendência significativa nas pesquisas em educação, apontando para a valorização dos processos de produção do saber docente a partir da prática e situando a pesquisa como um instrumento de formação de professores, em que o ensino é tomado como ponto de partida e de chegada da pesquisa (PIMENTA, 2002, p. 20 e 23).

Essa atitude, conforme Pimenta (2002), ao não levar em consideração que além de seu poder formativo a teoria dota os sujeitos de ideias, de pontos de vistas diferenciados para uma ação contextualizada, relega a importância da teoria na formação docente. Por conta disso, os saberes teóricos não podem ser desconsiderados. Ao contrário, devem se articular aos saberes práticos para resignificá-los e ser por eles resignificados. Ao vislumbrar os limites da proposta de Shön, Giroux (1990) irá desenvolver a concepção do professor como intelectual crítico, ou seja, cuja reflexão é coletiva no sentido de 
incorporar a análise dos contextos escolares no contexto mais amplo e colocar clara direção de sentido à reflexão.

É indiscutível, segundo Pimenta (2002, p. 43 e 47), a contribuição

da perspectiva da reflexão no exercício da docência para a valorização da profissão docente, dos saberes dos professores, do trabalho coletivo destes e das escolas enquanto espaço de formação contínua. Isto porque assinala que 0 professor pode produzir conhecimento a partir da prática, desde que na investigação reflita intencionalmente sobre ela, problematizando os resultados obtidos com o suporte da teoria. E, portanto, como pesquisador de sua própria prática. [...] a análise das contradições presentes na apropriação histórica e concreta desse conceito, evidenciadas na pesquisa teórica e empírica empreendida, subsidia a proposta de superar-se a identidade necessária dos professores de reflexivos para a de intelectuais críticos e reflexivos.

Apesar do desenvolvimento de um mesmo currículo no processo de formação de professor, a sequência de experiências de vida que contribuem ou contribuíram para forjar a personalidade, os conhecimentos, as competências, a relação com o saber e a identidade de cada um não se dão do mesmo modo. O domínio de sua individualização passa por dispositivos de acompanhamento e de regulação durante vários anos, o que lança vários desafios às instituições de formação entre os quais se impõe a reconstrução de uma arquitetura de conjunto.

No entendimento de Arroyo (2000, p. 41),

Toda tentativa de equacionar a formação de um educador esbarra no recorte da divisão geográfica e gradeada das disciplinas. Pensar e mexer com a formação humana é um pensar nossa própria formação, nosso próprio percurso. Nos enfrenta com um dever-ser. O que é bem mais complicado do que um saber-fazer. [...] É mais fácil questionar o sucesso ou o fracasso dos alunos no domínio de conteúdos e técnicas, de competências, do que o próprio mestre questionar a formação e o desenvolvimento humano dele próprio, porque será sempre uma auto-interrogação. O primeiro nos expõe a nossos domínios e competências, o segundo nos expõe a nossa emancipação da condução do educando.

Conforme Lyotard (1993, p. 120 apud ARROYO, 2000, p. 41), "não se pode ser mestre, no sentido de dominar esse curso. Não se pode expor uma questão sem ficar exposto a essa questão. Interrogar um 'tema' (a formação, 
por exemplo) sem ser interrogado por ele". Ser educador (mestre) é um modo de ser e um dever-ser pedagogo de nós mesmos, estabelecendo uma conversa constante com nós mesmos sobre a formação como o momento de aprender a ser pedagogo educador, que exige uma elaboração pedagógica que não pode ser confundida com a aprendizagem e o domínio de mais uma teoria, mas como a construção de um saber sobre o percurso pedagógico formador, portador de paciência, valorização, diálogo, reflexão, compreensão do percurso educativo.

As dimensões do dever-ser, conforme enfatiza ainda Arroyo (2000), não cabem num novo ou velho método. A formação do professor envolve mais do que uma nova metodologia, nova didática, nova estratégia de ensino, nova competência teórica a ser treinada em conjuntos de cargas horárias de requalificação com técnicas fechadas predeterminadas em cada semestre, medindo resultados, exige uma postura humana, pedagógica que deixe de tratar os saberes humanos como apenas conteúdos, matérias escolares, temáticas, conhecimento da disciplina de cada semestre ou ano letivo como precondições para passar de ano. O dever-ser que acompanha todo ato educativo e todo educador exige reflexão, leitura crítica, domínio de teorias e métodos, mas não se esgota aí seu aprendizado, porque situa-se no campo dos valores, da cultura.

A formação do professor deve ser desenvolvida através de práxis que podem possibilitar a transformação de si próprio e da realidade. Ela deve ser, segundo Vázquez (2011), uma atividade prática que é real e tem como norte o desenvolvimento do outro (aluno) e não uma simples aplicação para cumprir metas estabelecidas pelos programas ou por estruturas superiores. Assim sendo, ao aliarmos a pesquisa à formação e à pratica docente, garantimos que esta prática seja, de fato, práxis.

Por conta disso é necessário não apenas a reflexão sobre a prática docente nas pesquisas e nas teorias, mas também o desenvolvimento de uma consciência crítica - nível mais avançado da consciência, que representa o posicionamento do indivíduo frente as relações sociais porque a educação vai além disso e, por isso, exige do professor ações que levem ao despertar 
nos alunos a consciência crítica, ou seja, a capacidade de perceberem as relações que não estão imediatamente postas.

A consciência crítica se coloca, assim, em oposição à consciência alienada, a consciência que assume o mundo das obviedades humanas como naturalmente dado, onde tudo é obviamente natural, espontâneo e eterno. Portanto, é necessário fazer com que a consciência crítica não seja apenas um discurso estabelecido, onde todo o mundo fala que é necessário gerar um cidadão crítico e participativo, mas na prática não se chega ao desenvolvimento da consciência crítica porque a obviedade, a naturalidade, impedem o seu desenvolvimento.

O educador, segundo Mello (2000), pensa e atua na ótica da obviedade, apenas fala em consciência crítica, ou seja, ele anuncia algo que não sabe o que é e que, por isso, não pode ser traduzido em procedimentos que dirigem sua ação. Nesta perspectiva, a formação do professor precisa trabalhar para que os sujeitos em formação possam olhar para além do óbvio do fenômeno, questionando e refletindo com vistas à sua compreensão. Atitude que requer, por outro lado, o desenvolvimento de pesquisas voltadas para a formação de "intelectuais reflexivos e críticos", que sejam protagonistas na resolução dos problemas de aprendizagem que ele e os alunos enfrentam.

Quando se propõe a reflexão como conceito central no processo de formação de professores, conforme Giroux (1997 apud GHEDIN, 2009), estamos querendo dizer que eles não podem tornarem-se vítimas do sistema, não podem deixarem-se alienar, mas que precisam transpor os horizontes e os muros da alienação.

Conforme ensina Ghedin (2002, p. 131)

Na formação profissional do professor, fundada num paradigma reflexivo, um problema se coloca evidente: o modelo de formação que se orienta no positivismo pragmático não responde às necessidades concretas de um profissional que responda, mais amplamente, aos desafios contemporâneos. Isto quer dizer que não estamos diante de um problema exclusivamente prático como quer o modelo tradicional de orientação pragmática, mas frente a uma questão eminentemente epistemológica, isto é, o problema de formação dos professores não está centrado tanto no como formar 
bons profissionais da educação e sim, em quais os pressupostos que possibilitam e tornam possível uma proposta válida em detrimento e em oposição a outra. [...] as abordagens sobre o problema estão muito centradas em situações praticas, que não deixam de ser relevantes, mas que não fundamentam suficientemente uma perspectiva que possibilite um salto da prática, como ponto de partida, para a construção do saber pedagógico sistematicamente fundamentado.

Ao perguntar sobre a base epistemológica que fundamenta a atual proposta de formação dos profissionais de educação, o autor procura evidenciar uma problemática presente na formação de professores. Para ele,

\begin{abstract}
O caminho aberto pela necessidade da reflexão, como modelo de formação, propôs uma série de intervenções que tornou possível, ao nível teórico e prático, um novo modelo de ver, perceber e atuar na formação dos professores. Com todas as críticas e acréscimos que se façam à proposta feita por Shön, é inegável a sua contribuição para uma nova visão da formação. [...] a grande crítica que se coloca contra Shön não é tanto a realização prática de sua proposta, mas seus fundamentos pragmáticos. A questão que me parece central é que o conhecimento pode e vem da prática, mas não há como situálo exclusivamente nisto. É decorrente desta redução que se faz da reflexão situada nos espações estreitos da sala de aula que se situa sua crítica (GHEDIN, 2002, p. 131-132).
\end{abstract}

Ainda segundo Ghedin (2002), o conhecimento teórico é produto de uma relação estabelecida entre a prática e as nossas interpretações da mesma, é um modo de ver e interpretar nosso modo de agir no mundo. A capacidade de questionamento e de autoquestionamento é pressuposto para a reflexão. Não existe isolada. É resultado de uma ampla busca que se dá através de constante questionamento entre o que se pensa e o que se faz. A percepção da teoria e da prática como dois elementos de um mesmo objeto é essencial para que se compreenda o processo de construção do conhecimento. Quando essas duas realidades simultâneas são dissociadas separamos o que é inseparável porque não há teoria sem prática e nem prática sem teoria. Em decorrência de uma percepção alienada, não se consegue perceber a sua dialética. Ao se agir com consciência de sua simultaneidade e separação dialética, teoria e prática se realizam como práxis. 
No que diz respeito à formação de professores, há de se operar uma mudança da epistemologia da prática para a epistemologia da práxis, pois a práxis é um movimento operacionalizado simultaneamente pela ação e reflexão, isto é, a práxis é uma ação final que traz, no seu interior, a inseparabilidade entre teoria e prática. O processo humano de compreensão-ação é, intrinsecamente, uma dinâmica que se lança continuamente diante da própria consciência de sua ação. [...] a consciência-práxis é aquela que age orientada por uma dada teoria e tem consciência de tal orientação. Teoria e prática são processos indissociáveis. Separa-los é arriscar demasiadamente a perda da própria possibilidade de reflexão e compreensão. A separação de teoria e prática se constitui na negação da identidade humana (GHEDIN, 2002, p. 133).

A vivência da docência é geradora e produtora de conhecimento, mas isto não seria possível sem uma sistematização dos conhecimentos que passa por uma postura reflexiva e crítica do educador sobre suas próprias experiências. Fundamentar o saber docente na práxis, ou seja, na açãoreflexão-ação é romper com o modelo mecânico-tecnicista da pura transmissão de conteúdos produzidos por especialistas e orientar-se por um novo paradigma epistemológico que possibilita promover a emancipação do professor para não mais esfacelar e dividir o saber do ensino e da pesquisa porque é o professor quem deve articular o saber pesquisado com a sua prática, refletindo e avaliando as teorias a partir de sua ação, na experiência cotidiana.

\section{O TRABALHO PEDAGÓGICO COMO ATO EDUCATIVO INTENSIONAL}

Tomar a ação docente como fundamento do trabalho pedagógico envolve a formação de um profissional capaz de articular/mediar as atividades da educação: docência, gestão, supervisão e orientação como parte de um todo orgânico, tendo a docência não como domínio disciplinar, mas como um processo de construção e socialização de conhecimentos que visam contribuir para a formação do indivíduo em cada época de sua vida.

Para isso se faz necessário que aconteçam mudanças no processo de ensinar, que supere a visão da educação escolar sustentada nos conteúdos, apresentados como estáveis e universais e não como realidades socialmente construídas que, por sua vez, reconstroem-se nos intercâmbios de culturas que 
têm lugar na sala de aula. No lugar de apenas transmitir conteúdos, o professor precisa mobilizar as inteligências, sua e dos alunos, para desenvolver a capacidade de apreensão dos saberes e, a partir dela, construírem conhecimentos que possam ser objeto de transferência ou transmissão quando necessário.

Porque os valores sociais e os saberes disciplinares estão constantemente mudando, se faz necessário que tanto a educação quanto o ensino escolar sejam repensados a fim de que seja possível realizar a superação da redução da complexidade do ensino a um currículo escolar conteudista, centrado em disciplinas organizadas em compartimentos fechados que oferecem ao aluno algumas formas de conhecimento que pouco tem a ver com os problemas e saberes fora da escola, ligados às demandas de diferentes setores sociais, assim como a superação da incapacidade da escola para repensar-se de maneira permanente, dialogar com as transformações que acontecem na sociedade, nos alunos e na própria educação. É preciso fugir das amarras que

[...] impeçam de pensar por si mesmo, construir uma nova relação educativa baseada na colaboração na sala de aula, na escola e com a comunidade. [...] explorar novos caminhos que permitam que as escolas deixem de ser arquipélagos para converter-se em comunidade de aprendizagem, onde o interesse pelo conhecimento seja a divisa e a educação de melhores cidadãos o horizonte ao qual se dirigir (HERNÁNDEZ, 1998, p. 13).

Nem o ensino e nem a aprendizagem pode ser uma simples transposição automática, envolve um processo mental do sujeito em confronto com uma nova situação, com capacidade de encontrar, selecionar, integrar os recursos cognitivos de que dispõe para investir na compreensão e no domínio da situação. Ambos são indissociáveis da forma escolar de educação. Conforme ensina Perrenoud (2000, p. 57), "a pretensão de toda escolarização é preparar os alunos para reinvestirem suas aquisições em contextos variados dentro e fora da escola, em situações da vida cotidiana, profissional, política, familiar e pessoal". 
A possibilidade de pensar por si mesmo, de identificar e de resolver problemas depende, segundo Perrenoud (2000, p. 56), "da extensão e da solidez das aprendizagens básicas". Por conta disso é possível dizer que uma parcela dos alunos com fracasso escolar resiste às aprendizagens escolares porque não vê sentido nelas. Este problema parece estar diretamente relacionado às aquisições de conhecimentos também disciplinares descontextualizados na formação do professor.

Tanto a formação do professor quanto o ensino que ele realiza, não são terminais, mas permanentes e devem ocorrer durante todo o processo formal de educação. Conforme Astolfi (1996 apud PERRENOUD, 2000, p. 58), "hoje os saberes escolares parecem bem pouco escolares para muitos alunos e, até mesmo, algumas vezes, francamente estranhos". E esta falta de sentido das aprendizagens parece estar ancorada numa visão limitada das relações entre saberes escolares e práticas sociais e se constitui como uma parte das dificuldades de aprendizagem. Os alunos acumulam saberes, passam nos exames, mas não conseguem mobilizar o que aprenderam em situações reais, no trabalho e fora dele.

\begin{abstract}
A relação com o mundo e consigo mesmo dos professores, das crianças e adolescentes, os valores na sociedade da informação e da comunicação, os conhecimentos derivados da pesquisa e da reflexão sobre a escola e sua função, as problemáticas que abordam os campos do saber, são diferentes em cada sociedade e em cada tempo. Por isso mesmo é que a relação entre o currículo escolar e os problemas reais devem ser tratados (estudados) através do diálogo pedagógico, da pesquisa e da crítica como atitude dirigida a favorecer a aprendizagem na aula, [...] a função da escola não encher a cabeça dos alunos de conteúdo, mas, sim, contribuir para formá-los para a cidadania e oferecer-lhes, como já se indicou, elementos para que tenham possibilidades de construir sua própria história (HERNÁNDEZ,1998, p. 23).
\end{abstract}

O processo educativo, especialmente, o de ensino não pode prescindir da aquisição e construção do conhecimento. São esses momentos que irão embasar a transmissão ou transferência do mesmo. Uma boa apreensão do fato, objeto ou fenômeno possibilitará ao sujeito educador ou educando, dar sentido aos elementos apreendidos e transformá-los em conhecimento e, com isso, realizar a transferência ou transmissão do mesmo. Não existe 
aprendizagem sem compreensão do que foi ensinado. Se não há compreensão é porque não houve apreensão, mas, tão somente o recolhimento de informações advindas da percepção.

Uma educação, um ensino voltado para a compreensão, por parte dos alunos, da importância e do valor do conhecimento transmitido, organiza-se a partir da preocupação de como os alunos aprendem e da vinculação que o processo de aprendizagem e a experiência da escola possui em sua vida.

\begin{abstract}
A partir dessa perspectiva, o ensino da interpretação seria a parte central de um currículo que adota um enfoque para a compreensão, onde se tenta enfrentar desafio duplo de ensinar os alunos a compreender as interpretações sobre os fenômenos da realidade, a tratar de compreender os 'lugares' desde os quais se constroem e assim 'compreender a si mesmos'. [...] isso acontece quando estamos interessados em conhecer e situar diferentes interpretações da realidade, as origens dos fatos e os fenômenos que estudamos na sala de aula na escola (HERNÁNDEZ, 1998, p. 28).
\end{abstract}

Decorrente disso teríamos a ampliação do que Gadamer (1976) denomina de "horizonte do conhecimento" que, no contexto da escola, seria tanto dos alunos quanto dos professores. Para tanto é necessário que tenham disposição para aprender e, para continuar aprendendo é necessário um conhecimento prévio cuja natureza não precisa ser apenas acadêmica, podendo ser do sensu comum, fruto da experiência cotidiana ou relacionada com outros conhecimentos organizados não necessariamente científicos.

Isso nos leva a considerar que a forma de aproximar-nos do conhecimento escolar da qual aqui se trata não nos "fixa" em verdades sagradas, universais e estáveis, e sim nos situa na tentativa de encontrar o que há por trás do que parece natural e nos coloca numa atitude de incerteza frente ao papel que as diferentes linguagens que se refletem nos saberes, nas disciplinas, nas matérias, [...] representam nesse processo de dar sentido à realidade [...]. Também nos conduz a considerar a sala de aula como um cenário com uma cultura própria (mas não única). Cultura que se vai definindo mediante as diferentes formas do discurso que se desenvolvem e se encenam nas situações de aula (Idem, p. 29).

Segundo Hernández (1998), no repensar a escola deve ser levado em consideração uma perspectiva relacional do saber que se supõe ensinar a: 
a) Questionar toda forma de pensamento único, o que significa introduzir a suspeita sobre as representações da realidade baseada em verdades estáveis e objetivas.

b) Reconhecer, diante de qualquer fenômeno que se estude, as concepções que o regem, as versões da realidade que representam e as representações que tratam de influir em e desde elas.

c) Incorporar uma visão crítica que leve a perguntar-se a quem beneficia essa visão dos fatos e a quem marginaliza...

d) Introduzir, diante do estudo de qualquer fenômeno, opiniões diferenciadas, de maneira que o aluno comprove que a realidade se constrói desde de pontos de vistas diferentes, e que alguns se impõem frente a outros nem sempre pela força dos argumentos, e sim pelo poder de quem os estabelece.

e) Colocar-se na perspectiva de um certo "relativismo" no sentido de que toda realidade responde a uma interpretação...

O ensino e a transferência de conhecimentos não são terminais, são permanentes e devem ocorrer durante todo o processo da aprendizagem. A escola sofre da fragmentação dos problemas e dos conhecimentos. Sofre, também dos mecanismos que favorecem a transferência das aquisições.

Se uma parte dos jovens adultos oriundos da escolaridade obrigatória lê com muita dificuldade, se alguns correm o risco de tornarem-se analfabetos funcionais, não é apenas por não transferir um savoir-faire adquirido, é simplesmente por não tê-lo realmente construído durante sua escolaridade (PERRENOUD, 2000, p. 55).

\section{REFLEXÕES FINAIS}

As reflexões que passamos a desenvolver visam despertar consciências para pensar a educação como instrumento capaz de iluminar o caminho que leve a apreender os seus fundamentos, significados e sentido e, com isso, transformar a consciência de sua importância em conscientização.

Como vimos, a partir do século XX, surgiram várias teorias educacionais com vistas a orientar os professores para trilharem outros caminhos pedagógicos em seu ensinar. Um exemplo bastante conhecido e verbalizado recai sobre a teoria do professor crítico/reflexivo. A LDB de 1996 reformulou o formato do ensino e, com isso, possibilitou aos cursos de Formação (Licenciaturas), estabelecerem caminhos pedagógicos próprios nos seus processos educativos.

Além da expansão da formação regular de professores, assistimos nos últimos anos, a uma avalanche de cursos de educação continuada para 
professores visando dotá-los de melhores e maiores conhecimentos para que possam melhorar seu desempenho e, com isso, melhorar o processo ensino/aprendizagem. De modo geral, com muitas ressalvas, as condições de ensino foram melhoradas, especialmente nas grandes cidades. Ora, se estes fatores foram melhorados, então por que o aprendizado não melhorou?

No nosso entendimento, isto acontece porque o ensino, com raras exceções, também não melhorou. Continua-se a utilizar o livro didático que não possibilita nenhuma reflexão nem ao professor e nem ao aluno. Os conteúdos são repassados de forma automática, acrítica, sem qualquer questionamento ou ligação com a realidade do mundo da vida. Desse modo não existe construção, mas apenas repasse de conhecimentos.

Diferenciar a formação e o ensino é fazer com que cada aprendiz vivencie, tão frequentemente possível, situações fecundas de apreensão e construção de conhecimento sustentadas na reflexão e na crítica, seja por parte dos professores, seja por parte dos alunos. Mas para que isto aconteça é indispensável que se considere no ato de ensinar quatro questões fundamentais: o que ensinar; por que ensinar; para que ensinar; como ensinar. Se este caminho não for seguido, dificilmente haverá aprendizagem. O aluno poderá decorar para responder satisfatoriamente as questões e, com isso, ser aprovado. Mas dificilmente construirá ou desenvolverá conhecimentos.

A construção de conhecimentos está relacionada à epistemologia como reflexão, como vigilância crítica que visa o estabelecimento das relações entre as teorias e os fatos e, consequentemente, entre teoria e prática (práxis) que parece ter sido abandonada no processo ensino e aprendizagem. Decorrente disso, em vez de questionarmos constantemente os resultados da educação brasileira, deveríamos questionar os seus fundamentos, os princípios que a norteiam e as ações empreendidas para realizá-la.

$\mathrm{Na}$ formação de professores existem muitas teorias educacionais que tratam e tentam orientar os professores para levarem em consideração estas e outras questões de extrema importância no seu fazer educativo. O que não faltam são obras sobre professor reflexivo e crítico; sobre o fazer pedagógico 
inter, multi e transdisciplinar. No entanto, o que assistimos constantemente é a prevalência de um ensinar disciplinar, mesmo quando os conteúdos apresentados para a aprendizagem exigem uma relação inter, multi ou transdisciplinar.

Os cursos de formação de professores precisam urgentemente, ao nosso entendimento, levar em consideração que o futuro professor necessita apreender e desenvolver um processo metodológico (pedagógico) que leve em consideração os princípios e os fundamentos de uma epistemologia que proporcione a formação do professor como "intelectual crítico e reflexivo" que leve em consideração a realidade do mundo exterior, a estrutura multiestratificada da realidade, a existência de conexões entre os fenômenos; a finalidade; a conservação; a transformação, a identificação, a diferença, etc.

Porque, em vez disso, parece que os formadores em nível superior ou não, apenas estão repassando conhecimentos, levando informações aos educandos. E informação não é conhecimento. A formação de professores precisa despertar nos alunos a vontade de conhecer para que possam enfrentar mares desconhecidos onde a realidade não permaneça oculta a seus olhos; para ensinar, orientar os indivíduos na construção e no desenvolvimento de conhecimentos que Ihes possibilite viver uma vida digna, como pessoa e cidadão.

\section{REFERÊNCIAS}

ABBAGNANO, N. Dicionário de Filosofia. São Paulo: Mestre Jou, 1970.

ARROYO, M. G. Oficio de Mestre: imagens e auto-imagens. Petrópolis: Vozes, 2000.

BRITO, R. M. Caminhos metodológicos do processo de pesquisa e de construção de conhecimento. Manaus: EDUA, 2016.

CHARLOT, B. Ensinar, Formar: lógica dos discursos constituídos e lógica das práticas. Fortaleza: Educação em Debate, v.1, 2001.

FREIRE, P. Pedagogia da autonomia: saberes necessários à prática educativa. São Paulo: Paz e Terra, 1996. 
HERNÁNDEZ, F. Transgressão e Mudança na Educação: os projetos de trabalho. Trad. Jussara Haubert Rodrigues. Porto Alegre: ArtMed, 1998.

IMBERNÓN, F. A Educação no Século XXI: os desafios do futuro imediato. Trad. Ernani Rosa. Porto Alegre: Artes Médicas Sul, 2000.

JAEGER, W. Paidéia: a Formação do Homem Grego. Tradução Artur M. Pereira: 4 ed. São Paulo: Martins Fontes, 2001.

MELLO, S. A. Linguagem, consciência e alienação: o óbvio como obstáculo ao desenvolvimento da consciência crítica. Marília: UNESP - Marília Publicações, 2000.

NIELSEN NETO, H. Filosofia da Educação. São Paulo: Melhoramentos, 1988.

PERRENOUD, P. Pedagogia Diferenciada: das intenções à ação. Trad. Patrícia Chittoni Ramos. Porto Alegre: Artes Médicas Sul, 2000.

PIMENTA, S.G.; GHEDIN, E. (Orgs). Professor reflexivo no Brasil: gênese e crítica de um conceito. São Paulo: Cortez, 2009.

SÁNCHEZ VÁZQUEZ, A. Filosofia da Práxis. São Paulo: Expressão Popular, 2011.

SCHMITZ, E. F. O Homem e sua Educação: fundamentos de filosofia da educação. Porto Alegre, 1984.

Recebido em: 28 de setembro de 2021. Aprovado em: 10 de novembro de 2021. Publicado em: 23 de novembro de 2021. 